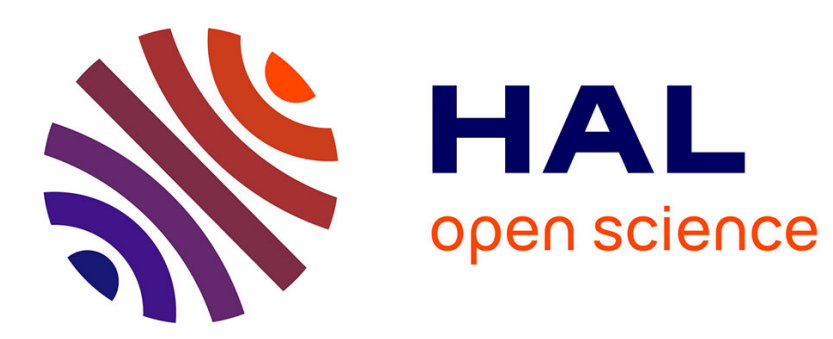

\title{
Auger electron microprobe analysis of the first steps of a Ni-20 Cr alloy oxidation
}

\author{
J.E. Schmitt, P. Pigeat, B. Weber
}

\section{To cite this version:}

J.E. Schmitt, P. Pigeat, B. Weber. Auger electron microprobe analysis of the first steps of a Ni20 Cr alloy oxidation. Journal de Physique IV Proceedings, 1993, 03 (C7), pp.C7-2169-C7-2172. 10.1051/jp4:19937345 . jpa-00251993

\section{HAL Id: jpa-00251993 https://hal.science/jpa-00251993}

Submitted on 1 Jan 1993

HAL is a multi-disciplinary open access archive for the deposit and dissemination of scientific research documents, whether they are published or not. The documents may come from teaching and research institutions in France or abroad, or from public or private research centers.
L'archive ouverte pluridisciplinaire HAL, est destinée au dépôt et à la diffusion de documents scientifiques de niveau recherche, publiés ou non, émanant des établissements d'enseignement et de recherche français ou étrangers, des laboratoires publics ou privés. 


\title{
Auger electron microprobe analysis of the first steps of a Ni-20 Cralloy oxidation
}

\author{
J.F. SCHMITT, P. PIGEAT and B. WEBER
}

Laboratoire de Science et Génie des Surfaces, URA 1402 du CRNS, INPL, Ecole des Mines, Parc de Saurupt, 54042 Nancy cedex, France

\begin{abstract}
In this paper, we present the study of the influence of a mechanical predeformation (uniaxial deformation) on the first steps of the oxidation at $750^{\circ} \mathrm{C}$ and under low oxygen pressure of a polycristalline $\mathrm{Ni}-20 \mathrm{Cr}$ alloy. Our experiments show that the defects induced by the mechanical deformation strongly enhance the superficial oxidation of chromium (the chromium oxide is the only superficial oxide detected in our experimental conditions). For instance, it involves a considerable decrease of the incubation period which precedes all the oxidations at $750^{\circ} \mathrm{C}$. The Auger microanalysis of many areas of oxidized samples reveal that the oxide distribution is heterogeneous but also that the oxide growth depends on the crystallographic orientation of the substrate. Furthermore, incorporated oxygen at concentrations higher than the limit solubility is detected in the alloy matrix near areas where superficial chromium oxide has developped. This last phenomenon is related to an internal oxidation process which occurs at the beginning of the reaction.
\end{abstract}

\section{INTRODUCTION}

Although it is now well established that a film of chromium oxide provides one of the most effective barriers to further $\mathrm{Ni}-\mathrm{Cr}$ alloys oxidation, many studies show that the oxidation mechanisms of these binary alloys are complex and governed by many parameters $[1-6]$, such as the oxygen pressure $[1,3]$, the oxidation temperature ${ }^{[3,6,8]}$, the mechanical stresses in the alloy sample and/or the alloy grain size ${ }^{[5-8]}$, the presence of impurities and/or additionnal elements at the extreme surface, etc. [1-3,9-11]. Since it has been established that deformed surfaces usually promote the selective oxidation of chromium when the $\mathrm{Ni}$ $20 \mathrm{Cr}$ alloy is oxidized under an high oxygen pressure (atmospheric pressure for instance)[5-8], we have decided to examine the influence of a uniaxial predeformation on the first steps of the oxidation of this alloy (low oxygen pressure : $3,3.10^{-4} \mathrm{~Pa}$ ) in the temperature range $550-830^{\circ} \mathrm{C}$ and in well-controlled conditions [12]. The purpose of this paper is to particularly present typical oxidation results obtained at the temperature of $750^{\circ} \mathrm{C}$ for predeformed and non predeformed alloy samples.

\section{EXPERIMENTS}

All our specimens are prepared from $0,15 \mathrm{~mm}$ thick ribbon of $\mathrm{Ni}-20 \mathrm{Cr}$ alloy from Imphy S.A. They are ultrasonnically cleaned in methanol, rinsed in distilled water before introduction into the vacuum chamber where they are pretreated, then oxidized. The ribbons are fixed on a tensile testing machine well adapted to ultrahigh vacuum and integral with a manipulator. The apparatus, described in a previous paper ${ }^{[13]}$, allows to deform a sample in situ before oxidation, to heat it to a high temperature by Joule effect, and to adjust its position in front of an Auger analyser with which we continuously follow the oxidations. The samples are annealed and cleaned by ionic bombardment in situ for 2 hours at $1120^{\circ} \mathrm{C}$ under argon. The average post-anneal grain size is about $190 \mu \mathrm{m}$ and the only residual contaminants detected at the oxidation temperature by Auger Electron Spectroscopy (A.E.S.) are small quantities of Si and $P$. 
So as to compare the oxidation behaviour of a $10 \%$ mechanically deformed ribbon to that of a reference ribbon (non predeformed ribbon), two samples are pretreated together, then oxidized in any order. Only one ribbon is $10 \%$ deformed under oxygen at ambiant temperature before oxidation.

The Auger spectrometer (Riber, France) has a cylindrical miror analyser (CMA) and is used in the following conditions : Auger derivative $\mathrm{E} \cdot \mathrm{dN}(\mathrm{E}) / \mathrm{dE}$ mode, primary beam energy Ep $=1500 \mathrm{eV}$, sample current Ie $=50 \mu \mathrm{A}$, modulation voltage : $5 \mathrm{~V}$, detection voltage sensibility : $10 \mathrm{mV}$. We record versus oxidation time the peak to peak amplitude of the Auger signals of nickel $\left(\mathrm{h}_{\mathrm{Ni}}, 848 \mathrm{eV}\right)$, that of oxygen (hO, $512 \mathrm{eV}$ ) and that of chromium ( $\mathrm{h}_{\mathrm{Cr}}{ }^{*}$, negative peak height because of the overlapping of oxygen and chromium peak). Because of the spot diameter of the electron beam (near $300 \mu \mathrm{m}$ ) and of the average grain size of our samples $(190 \mu \mathrm{m})$, the recorded Auger signals give us an average oxidation behaviour of each sample. After oxidations, each couple of samples is placed into an other apparatus for a detailed study of the oxide distribution. Surface microanalysis are then carried out using a scanning Auger microprobe : this apparatus allows us to establish Auger depth profiles of many points of the oxidized specimens (analysed area : $250.10^{-3} \mu \mathrm{m}^{2}$ ). The depth composition profiling is done with $5 \mathrm{KV} \mathrm{Ar}{ }^{+}$. The sputter rate of the surface is estimated to be $1,5 \mathrm{~nm} / \mathrm{mn}$ under an ion beam current of $10 \mu \mathrm{A}$. The first monolayers of the samples are systematically eliminated by ion bombardment because of air contamination during transfer to the second apparatus. For all the oxidations, we normalize the recorded Auger signals by using the relative sensitivity factors $\mathrm{s}_{\mathrm{Ni}}=0.27, \mathrm{~s}_{\mathrm{Cr}}=0.29$ and $\mathrm{s}_{\mathrm{O}}=0.50$ experimentally determined by Davis et al.[14]. The normalized signals, represented in arbitrary units, give us a good representation of the superficial composition of the sample at a given time of the reaction. Such a way to normalize our experimental signals has also been adopted for the Auger depth profiles with the following relative sensitivity factors : $\mathrm{s}_{\mathrm{Ni}}=1$, $\mathrm{s}_{\mathrm{Cr}}=1, \mathrm{~s}_{\mathrm{O}}=1.72$ (primary beam energy of $30 \mathrm{KV}$ for these experiments).

\section{RESULTS AND DISCUSSION}

\section{Oxidation curves}

Typical curves of oxidation at $750^{\circ} \mathrm{C}$ and under $3,3 \cdot 10^{-4} \mathrm{~Pa}$ of oxygen are given in figure 1 (fig.1.a: reference sample, fig.1.b: predeformed sample). First consider the case of the reference sample (fig.l.a). The initial Auger values (at $\mathrm{t}=0 \mathrm{mn}$ ) correspond with the sample with chemisorbed oxygen at ambiant temperature. At the beginning of the oxidation, important variations of the Auger signals are recorded : they are due to the oxygen incorporation in the alloy matrix (process of internal oxidation confirmed by the Auger microprobe analysis) and to a chromium segregation induced by the presence of oxygen. After this first step, the Auger signals are relatively stable till approximatly the end of the experiment : it corresponds with a long incubation period. A decrease of $\mathrm{H}_{\mathrm{Ni}}$, associated with an increase of $\mathrm{H}_{\mathrm{Cr}}$, are detected at the end of the reaction : this phenomenon is related to the very beginning of the growth of the superficial chromium oxide. The curves of the predeformed sample (fig.l.b) have the same aspect as the preceding and the same steps are recorded. However, the incubation period is here shorter than that of the reference ribbon and, consequently, the chromium oxide signals are reached more rapidly. At the end of the oxidation, the very small value of $\mathrm{H}_{\mathrm{Ni}}$ indicates that the sample surface is almost entirely covered by chromium oxide.

\section{Auger microanalysis of the oxidized samples}

So as to complete such experimental results and especially to precise the chromium oxide distribution, Auger microanalysis of the oxidized samples have been realised. Three types of Auger depth profiles (labelled types $I, I I$ and $I I I)$ have been obtained :

\section{* Auger profiles type I and II}

Profiles type I (fig. 2 ) correspond to the most oxidized areas of the deformed sample. They typically show between 30 and $50 \mathrm{~nm}$ thick chromium oxide layer essentially free of $\mathrm{Ni}$. A second layer is then detected : it is characterized by an increasing $\mathrm{H}_{\mathrm{Ni}}$ signal and by a nearly constant $\mathrm{H}_{\mathrm{O}} / \mathrm{H}_{\mathrm{Cr}}$ ratio. This layer is probably due to the heterogeneity of the superficial chromium oxide distribution and/or to internal oxide particles in the alloy matrix. At the end of the sputter, the low values of $\mathrm{H}_{\mathrm{Cr}}$ reveal a chromium depletion in the underlying alloy. Note that Auger profiles type II have nearly the same characteristics as the preceding except the fact that they reveal an increase of the $\mathrm{H}_{\mathrm{Ni}}$ signal since the beginning of the sputter. So, it proves that the chromium oxide film is not yet uniform for the analysed areas. 


\section{* Auger profiles type III}

The Auger profiles type III (fig.3) correspond to the fewest oxidized areas of the both samples. Since the beginning of the sputter, they reveal high nickel concentrations (high values of $\mathrm{H}_{\mathrm{Ni}}$ ), oxygen concentrations higher than the limit solubility but also a continuous decrease of the $\mathrm{H}_{O}$ signal versus sputter time. This phenomenon is related to an internal oxidation process occuring at the beginning of the reaction.

The fact that such profiles have been obtained on most of the grains of the reference sample confirms that the superficial chromium oxide has not developped, except on certain rare areas (a profile type II has been obtained for these last areas). Furthermore, these profiles are in good agreement with the long incubation period recorded during the oxidation of this same sample (fig.1).

Certain analysis of two areas on both sides of a twin plane give two different profiles. This fact clearly shows that the growth of the superficial chromium oxide is also influenced by cristallographic orientation of the substrate.

Finally, certain rare areas of the deformed sample, which are free of superficial chromium oxide, give profiles of this type.
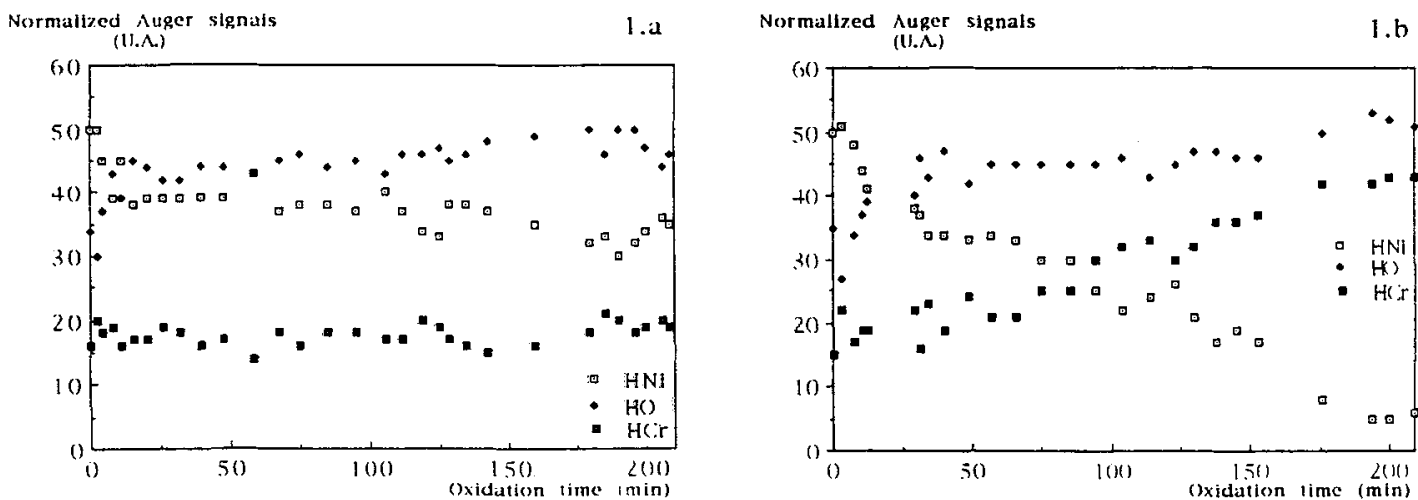

Figure 1: Typical oxidations curves of $\mathrm{Ni}-20 \mathrm{Cr}$ alloy samples (oxidation conditions : $750^{\circ} \mathrm{C}$ and $3,3.10^{-4} \mathrm{~Pa}$ of oxygen).

(a) reference sample.

(b) predeformed sample .
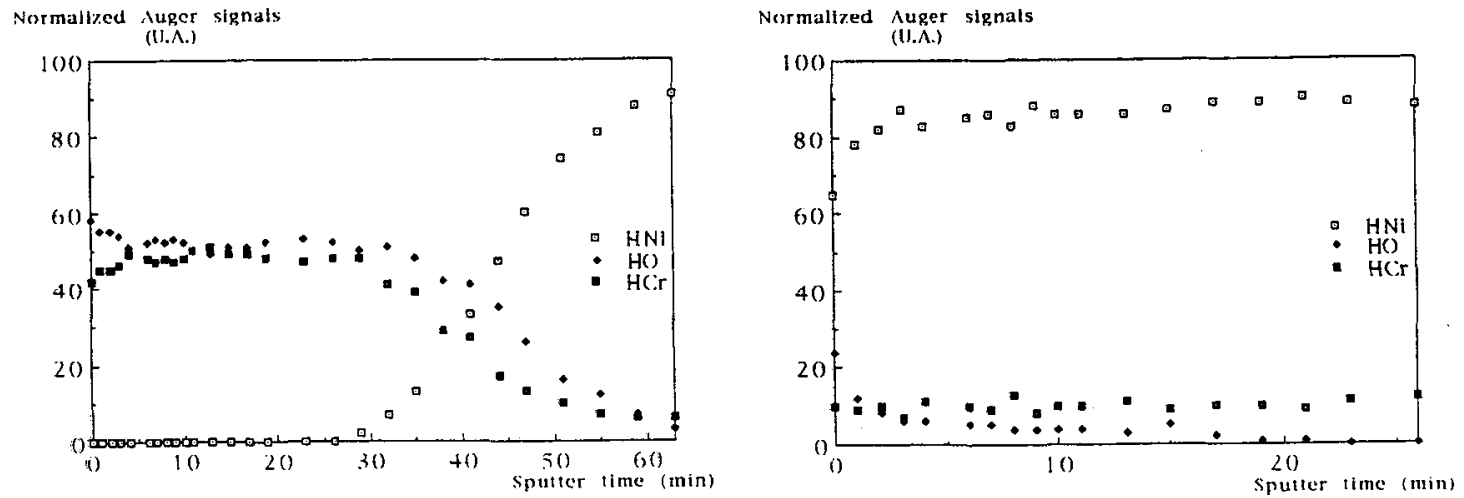

Figure 2: Auger depth profile of the most oxidized areas of the deformed sample (profile type I).

Figure 3 : Auger profile of the fewest oxidized areas of both samples (profile type III). 


\section{CONCLUSION}

The influence of a $10 \%$ mechanical deformation on the initial oxidation of a $\mathrm{Ni}-20 \mathrm{Cr}$ alloy has been studied. Our experimental conditions promote the growth of superficial chromium oxide, whether the sample is deformed before oxidation or not.

The essential effect of the mechanical predeformation is to reduce the incubation period which precedes all the oxidations at $750^{\circ} \mathrm{C}$ : this phenomenon is believed to be due to an increase of the superficial defects number which act as many additionnal nucleation sites and/or perhaps of the volumic defects. In this last case, the deformation should facilitate the diffusion in the alloy matrix.

The microanalysis of oxidized samples are in good agreement with the corresponding oxidations curves. They reveal that the superficial chromium oxide has not yet developped in the case of the reference sample while most of the areas of the deformed sample are covered with an uniform or not yet totally uniform film of chromium oxide.

These analysis confirm that the growth of the superficial chromium oxide depends on the cristallographic orientation of the substrate and especially on its metallurgical state. Finally, they allow us to show that there is a non negligeable competitive process of internal oxidation which occurs at this oxidation temperature.

\section{REFERENCES}

1. G. C. Wood, Werkst. Korros. 6,491 (1971).

2. G. C. Wood, Oxid. Met. 2,11 (1970).

3. P. Kofstad, High Temperature Corrosion. Elsevier Applied Science, New York (1988).

4. C. S. Giggins and F. S. Pettit, Trans. Met. Soc. AIME 245, 2509 (1969).

5. C. S. Giggins and F. S. Pettit, Trans. Met. Soc. AIME 245, 2495 (1969).

6. P. Moulin, F. Armanet, G. Beranger and P. Lacombe, Mem. Sci. Rev. Met. 143 (1977).

7. C. S. Giggins and F. S. Pettit, Trans. Met. Soc. AIME 245, 2495 (1969).

8. F. Armanet, Compiegne thesis (1984).

9. C. H. Yang, G. Welsch, T. E. Mitchell, J. Mat. Sci. 25, 1724 (1990).

10. H. Nagai, Mat. Sci. For. 43,75 (1989).

11. D. N. Braski, P. D. Goodell, J. V. Cathcart and R. H. Kane, Oxid. Met. 25, 29 (1986).

12. J. F. Schmitt, thesis (Nancy, France) (1992).

13. J. F. Schmitt, M. Bouhay, N. Pacia, P. Pigeat and B. Weber, Rev. Sci. Inst., 61, 2666 (1990).

14. L. E. Davis, N. C. Macdonald, P. W. Palmberg, G. E. Riach and R. E. Weber, Handbook of Auger Electron Spectroscopy, Physical Electronics Industries Inc (1976). 